\title{
YO TENGO UN CONCEPTO DRAMÁTICO DE LA VIDA..., Y ROMÁNTICO
}

\author{
PACO TOVAR
}

\author{
- ¿Cómo describirías a un ser bumano po- \\ siblemente completo? \\ - Político, poético. Físico.
}

Pablo Neruda reconoce haber forjado siempre las piezas de una sola obra, cumpliendo así un viejo deseo: nombrar lo que ha visto y conoce, tarea descubridora que, por entrañable, no tiene límites, agota etapas y genera nuevas experiencias de cuño literario:

...me acurruqué en mis sentidos y seguramente me dispuse a acumular y pesar mis materiales, para una construcción que tal vez pensé, y ahora confirmo, duraría hasta el final de mi vida ${ }^{1}$.

Ese propósito nerudiano responde a la naturaleza de un yo esencialmente romántico, pero de talante humanista ${ }^{2}$; devuelve a la escritura su antigua función testimonial, de ningún modo objetiva ${ }^{3}$; deriva con la historia, moldeándola en conciencia; guarda secretos, pulsando verdaderas emociones; trata de acordar fondo y forma, sin prejuicios críticos o estéticos; y airea en última instancia un espectáculo de carne y hueso, rigurosamente organizado al pie de la letra. Todas esas líneas de actuación imponen sus reglas, dibujando un mapa creativo y geográfico de amplio espectro, dimensiones particulares y tremenda originalidad:

No me gusta considerar la originalidad como un fetiche. Buscar a toda costa la originalidad es un pro-
Paco Tovar

Catedrático de literatura hispanoamericana de la Universitat de Lleida. Es autor de libros sobre Augusto Roa Bastos y antologías sobre este autor y de una visión múltiples de autores y problemas de la literatura hispanoamericana del siglo XX (Contrapunto). Ha publicado además numerosos artículos sobre vanguardias, Vicente Huidobro, Juan Carlos Onetti, Mario Monteforte, Alejo Carpentier, etc.

blema moderno [...] Yo pienso que el problema de la originalidad debe solucionarse en cada ser, expresando en forma más auténtica tanto su propia existencia y su propia experiencia como su propio lenguaje. Esta necesidad expresiva naturalmente se irá definiendo. Por lo demás, aún así, el artista más original cambiará de fases de acuerdo con el tiempo, con la época, con los temas4.

Pablo Neruda, «Mariano Latorre, Pedro Prado y mi propia sombra», en Hernán Loyola (ed.), Obras Completas. Nerudiana dispersa I, vol. IV, Barcelona, Círculo de LectoresGalaxia Gutemberg, p. 1093 (en adelante, todas las citas nerudianas remiten a esta edición de las O.C., especificando el título que identifica el texto original y el volumen donde localizarlo).

\section{2}

Pablo Neruda, «Mariano Latorre, Pedro Prado y...», op. cit., p. 1094. Uno de los fundamentos literarios de de Pablo Neruda es la comunión entre sujeto y escritura, entre impulso y razón:

..mi trabajo debía producirse en forma tan orgánica y total, que mi poesía fuera como mi propia respiración, producto acompasado de mi existencia, resultado de mi conocimiento natural.
3

Pablo Neruda confiesa que ha procurado despojar la poesía de todo lo objetivo, pero guardando las formas (Raúl Silva Castro, «Una hora de charla con Pablo Neruda», O.C. Nerudiana dispersa II, vol. V., p. 1050. El original de la entrevista se publicó en El Mercurio, Santiago, 10-X-1926). Reconoce también haber tratado de englobar en su escritura no sólo al hombre, sino a la naturale$z a$, a las fuerzas escondidas. En última instancia, el yo nerudiano establece las reglas oportunas de un quehacer estético sugerente y misterioso, anclado en la realidad, decantado a conciencia y como verdadero testimonio de simple apariencia y hondo calado:

El poeta debe ser, parcialmente, el CRONISTA de su época. La crónica no debe ser quitaesenciada, ni refinada, ni cultivista. Debe ser polvorienta, lluviosa y cotidiana. Debe tener la huella miserable de los días inútiles y las execraciones y lamentaciones del hombre. ("Algunas reflexiones improvisadas sobre mis trabajos», en O.C Nerudiana dispersa I, vol. IV, op. cit., p. 1205. Expuesto por el autor en la Biblioteca Nacional de Santiago de Chile, la confesín habría de publicarse en Mapocho, II, no 3, 1964).

4

Rita Guibert, "Conversación frente al océano», en O.C. Nerudiana dispersa I, op. cit., p. 1162. (realizada en la Isla Negra, del 15 al 31 de enero de 1970, la entrevista se publicaría en Siete voces, México, Editorial Novaro, 1974). El concepto nerudiano de originalidad entraña el sólido aprendizaje literario del poeta, descubre sus variaciones y responde a un ejercicio de conocimiento sensible, inteligente y forjado a golpes de historia:

La literatura tiene que ser una experiencia profundamente personal en la que interviene el tiempo, la realidad y el sueño. $Y$ hay que dejar que estos tremendos materiales se sitúen y se desplacen de acuerdo no sólo a la intimidad del escritor, sino también a la época en que vivimos. ("Conversaciones frente al océano», op. cit., p. 1162).

Yo tengo un concepto dramático de la vida..., y romántico 


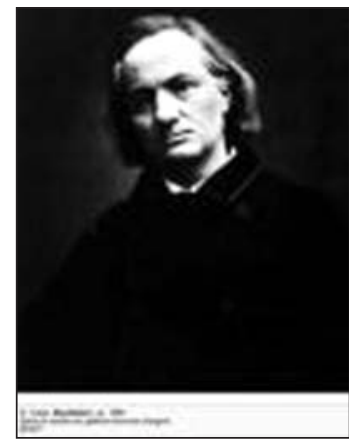

Baudelaire.

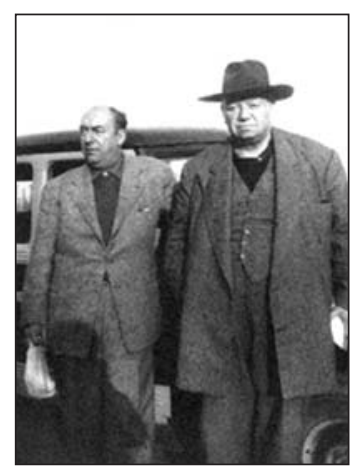

Con Diego Rivera en 1953 en Chile.

5

Pablo Neruda, «Mariano Latorre, Pedro Prado y...», op. cit., p. 1095. Las querencias literarias declaradas por Neruda muestran en primer lugar el talante poético del anfitrión, situándolo entre pares y añadiendo necesarios contrapuntos.

6

Pablo Neruda, «Conversaciones frente al océano», op. cit., pp. 1160-1161. Resuelve así Neruda el viejo debate sobre las filiaciones literarias puras, entendiendo que los artificios realistas - las imaginerías simbólicas tienen sólo valor instrumental. Ambos registros estéticos, empleados sin engaño, pueden manejarse al compás de la verdadera representación.

7

Pablo Neruda, "Mariano Latorre, Pedro Prado y...», op. cit., p. 1093. La sinceridad reclamada por Neruda puede interpretarse como un gesto de orgullo personal, sin consecuencias, pero descubre la filiación estética nerudiana, censura criterios aje-

Yo tengo un concepto dramático de la vida..., y romántico PACO TOVAR

Planteada en sus términos, la poética de Neruda se mueve al compás de la tradición, reconoce magisterios, equilibra fuerzas contrarias, permite oscilaciones, vadea escuelas y juega con sinceridad.

El mundo de las artes es un gran taller en el que todos trabajan y se ayudan, aunque no lo sepan ni crean. Y, en primer lugar, estamos ayudados por el trabajo de los que precedieron y ya se sabe que no hay Rubén Darío sin Góngora, ni Apollinaire sin Rimbaud, ni Baudelaire sin Lamartine, ni Pablo Neruda sin todos ellos juntos. Y es por orgullo y no por modestia que proclamo a todos los poetas mis maestros, pues, qué sería de mí sin mis largas lecturas de cuanto se escribió en mi patria y en todos los universos de la poesía?

$[\ldots]$

El debate entre poesía pura y poesía impura es un debate inútil [...]. Yo me quedo con las dos [...]. Es decir, yo quiero que mi poesía exprese el hermetismo del alma y exprese la simplicidad de las cosas elementales más cercanas al ser humano. $[\ldots]$

nos y mantiene las oportunas distancias con el sincero Huidobro:

El escritor desoído y atrapado contra la pared por las condiciones mercantilistas de una época cruel ha salido a menudo a la plaza a competir con su mercadería, soltando sus palomas en medio de la vociferante reunión. Una luz agónica entre crepúsculo de la noche y sangriento amanecer lo mantuvo desesperado y quiso romper de alguna manera el silencio amordazante. "Soy el primero», gritó; "soy el único», siguió repitiendo con incesante $y$ amarga egolatría.

Se vistió de príncipe como D'Anunzzio y no dejó de incitar al estupefacto cadumen de las playas este atrevido falsificador de la audacia. ("Mariano Latorre, Pedro Prado...», op. cit., p. 1092).

[...]

..a pesar de la infinita destreza, del divino arte de juglar de la inteligencia y de juego intelectivo que yo admiraba en Vicente Huidobro, me era totalmente imposible seguirlo en ese terreno, de-
Yo participo de la creencia, de la posición, de que la realidad tenga parte espléndida y definitiva en la visión literaria, así como no creo en el realismo literario. De igual manera, creo que el símbolo, desde la escuela francesa, o desde muy anteriormente, nunca perdió su importancia. El símbolo es una de las reglas de la creación poética, pero sin embargo el símbolo como escuela, es un vasto cementerio de símbolos [...] Realidad y símbolo seguirán formando parte de todo el movimiento de fecundidad, del desarrollo de la literatura. En cierto plano se mezclan y se confunden, pero como escuelas pueden ser funestas ${ }^{6}$.

$[\ldots]$

Sinceridad, en esta palabra tan modesta, tan atrasada, tan pisoteada y despreciada por el séquito resplandeciente que acompaña a la estética, está tal vez definida mi constante acción?.

Con Darío, Apollinaire, Rimbaud, Baudelaire y Góngora, organiza esta vez Pablo Neruda un baile donde las parejas, cuidadosamente seleccionadas, quiebran cinturas, inauguran su escándalo y dan pie a otros equilibrios. Ellos no agotan los huéspedes instalados en la memoria nerudiana, que citará en ocasiones al hilo de la conversación, reservando un saludo más íntimo a quienes lograron brindarle fantasías dignas de recuerdo:

ción, todo mi ser más profundo, mi tendencia y $\mathrm{mi}$ propia expresión eran antípodas de esa misma destreza de Huidobro ("Algunas reflexiones sobre mis trabajos», op. cit., p. 1204).

8

Ibidem., p. 1096. Neruda remite a una nómina sentimental de autores que proporcionaron al escritor, en tiempos de juventud, verdaderas fantasías. Estas últimas referencias no desmerecen ante las de mayor entidad (nota 5) y todas fueron

...un acompañamiento oriental que transformó, por un minuto, a nuestra pobre patria cordillerana en un gran salón alfombrado y dorado, todo el mundo de las tentaciones, de todos los libros, de todos los ritmos, de todos los idiomas, de todas las abejas, de todas las sombras, el mundo, en fin, de toda la afirmación poética, me impregnó de tal manera que fui sucesivamente la voz de cuantos me enseñaron una partícula, pasajera o eterna, de la belleza (Ibidem., p. 1096).
Hemos llegado dentro del intelectualismo militante a escoger hacia atrás, escoger aquellos que previeron los cambios y establecieron nuevas dimensiones. Esto es falsificarse a sí mismo falsificando los antepasados.

\section{$[\ldots]$}

En cuanto a mí, recibí el impacto de libros desacreditados ahora, como los de Felipe Trigo, carnales y enlutados con esa lujuria sombría que siempre pareció habitar el pasado de España, poblándolo de hechicerías y blasfemias. Los floretes de Paul Fecal, aquellos espadachines que hacían brillar sus armas bajo la luna feudal, o el ínclito mundo de Emilio Salgari, la melancolía fugitiva de Albert Somain, el delirante amor de Pablo y de Virginia, los cascabeles tripentálicos de Pedro Antonio González... ${ }^{8}$

El anfitrión de tan bulliciosa fiesta, repleta de goces privados, advierte a los extraños curiosos el perfil dominante que lo identifica, en clave chilena y expuesto a los contrastes:

Yo aprendí desde pequeño a leer el lomo de las lagartijas que estallan como esmeraldas sobre los viejos troncos podridos de la selva sureña, y mi primera lec- 
ción de inteligencia constructora del hombre aún no he podido olvidarla.

[...]

Yo soy un patriota poético, un nacionalista de las gredas de Chile. Nuestra patria conmovedora.

[...]

Aquí siempre me pasó otra cosa. Se conmueve aún mi corazón $[\ldots]$ con esas casas de madera, con esas calles destartaladas que comienzan en Victoria y terminan en Puerto Montt, y que los vendavales hacen sonar como guitarras. Casa en que el invierno y la pobreza dejaron una escritura jeroglífica y que yo comprendo, como comprendo en la pampa grande del norte, mirada desde Huantajaya, ponerse el sol sobre las cumbres arenosas que toman entonces los colores intermitentes, arrobadores, fulgurantes, resplandecientes o cenicientos del cuello de toscaza silvestre.

$[\ldots]$

[la escritura] es una profesión errante y ya se sabe que en todas partes me toman, a orgullo lo tengo, no sólo como a un chileno más, que no es poco decir, sino como a un compañero más, que ya es mucho decir. Ésta es mi arte poética?.

El resto del mundo siempre resultará extraño para un viajero inmóvil. Oriente, tierra de colores violentos y atavismos sórdidos, donde las bestias y el pasisaje lo amenazaban de alguna manera y eran indescifrables; las resecas colinas del Perú, misterioso y metálico; las pampas argentinas, inabarcables; un México, que amó sin llegar a comprenderlo; los Montes Urales, cuna de la justicia y la verdad de nuestro tiempo; y hasta París, repleto de gentes, ámbito de la culta más universal y lugar de soledades.

\section{...un bardo asume...}

Mochila sencilla y equipaje cosmopolita son las diferentes cargas de un hondero entusiasta y de un hombre infinito, ambos una sola persona que supo apreciar en Shakespeare a un viejo amigo; también compañero de aventuras extraordinarias. Quizás por sus esgrimas de corte dramático y porque sabe manejar con fuerza el difícil arte poético. Él, ya de Pablo Neruda, creó personas, tuvo a bien nombrarlas y llegó a soplarles vida en los escenarios, revelando así padecimientos y remordimientos, martirios y crueldades. Ellos continúan representando

....seres de sangre, criaturas del aire, voces que se iluminan para una fiesta mágica, banquetes a los que acu-

den los fantasmas ensangrentados. Y tantas luchas, y tantas almas, y tantas pasiones, y toda la vida ${ }^{10}$.

En distintas épocas, otros lugares y a gritos entrañables, Shakespeare tiene sus cómplices dignos de asumir la totalidad de los sueños y de la sabiduría; el crecimiento, la expansión del mundo. Léase por ejemplo Alighieri, Hugo, Lope de Vega o Walt Whitman. Todos se llaman Shakespeare, como desea Neruda

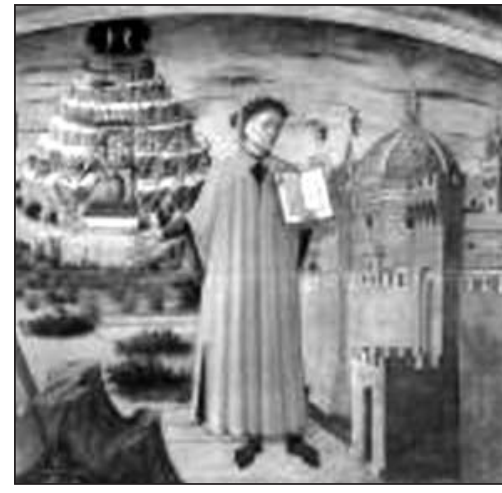

Dante Alighieri.

...estos bardos acumulan hojas, pero entre estas hojas hay trinos, bajo estas hojas hay raíces. Son hojas de grandes árboles.

Son hojas y son ojos. Se multiplican y nos miran a nosotros, pequeños hombres de todas las edades transitorias, nos miran y nos ayudan a descubrirnos: nos revelan nuestro propio laberinto ${ }^{11}$.

Pequeña es la distancia entre las piezas visionarias elaboradas por el dramaturgo que oficia de cómico y las huellas del mismo en sonetos que

...fueron cortados en el ópalo del llanto, en el rubí del amor, en la esmeralda de los celos, en la amatista del luto.

Fueron cortados por el fuego, fueron hechos de aire, fueron edificados de cristal.

Los sonetos fueron arrancados a la naturaleza de tal manera, que desde el primero al último se oye cómo transcurre el agua, y cómo baila el viento, y cómo suceden, doradas o floridas, las estaciones y sus frutos. Los sonetos tienen infinitas claves, fórmulas mágicas, estática majestad, velocidad de flechas.

Los sonetos son banderas que una a una salieron de las alturas del castillo. Y aunque todas soportaron la intemperie y el tiempo, conservan sus estrellas de color amaranto, sus mediaslunas turquesa, sus fulgores de corazón incendiado ${ }^{12}$.

9

Ibidem., p. 1097-1098. El juego nerudiano de contrastes no se agota en quiebros de salón; identifica su paisaje, va dejando huellas y reclama interlocutores afines, organizando así en clave romántica todas sus experiencias de vida, sin agotarlas:

Mi canto no termina. Otros renovarán la forma y el sen- tido. Temblarán los libros en los anaqueles y nuevas palabras insólitas, nuevos signos y nuevos sellos sacudirán las puertas de la poesía. (ibidem., p. 1101).

10

Pablo Neruda, «Los dos cumpleaños de 1964: Shakespeare $\left(400^{\circ}\right)$ y Neruda $\left(60^{\circ}\right) »$, O.C. Nerudiana dispersa I,

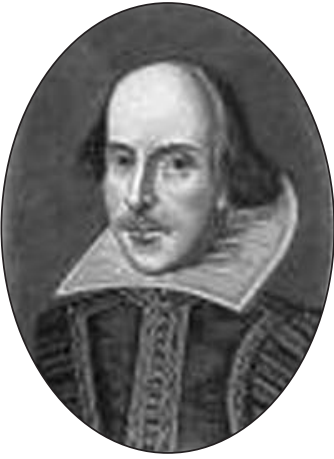

Shakespeare

op. cit., p. 1197. El original se publicó en los Anales de la Universidad de Chile, no 129, Santiago, enero-marzo, 1964.

11

Ibidem., p. 1197. Dante, Hugo, Lope de Vega y Walt Whitman son para Neruda referencias literarias de singular entidad, pero entre ellas destaca Shakespeare, con su yo múltiple dispuesto a mirar de frente: Goneril, Regan, Hamlet, Angus, Duncan, Glansdale, Mortimer, Ariel, Leontes...., son algo más que personajes sometidos a una forma dramática; tienen vida en sí mismos y logran impresionar desde la escena con sus acciones dramáticas. Lope de Vega podría ser la versión española de Shakespeare, pero más inclinado hacia los estereotipos escenográficos y la comedia social.

12

Ibidem., p. 1198.

Yo tengo un concepto dramático de la vida..., y romántico PACO TOVAR 


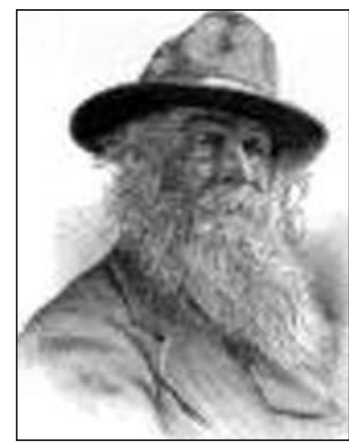

Whitman.

13

Pablo Neruda, «Los dos cumpleaños...», op. cit., p. 1199.

La realidad poética de Shakespeare supera el ámbito de lo material, instalándose con verdadero sentido en las entrañas cotidianas del hombre.

14

Ibidem, p. 1198.

15

Pablo Neruda, «Final», Crepusculario, en O.C., vol I, op. cit., pp. 154-155.

16

Pablo Neruda, [Yo me llamaba Reyes, Catrileo], El mar y las campanas, en O.C., vol III, op. cit., p. 911

«Mis ojos», Los cuadernos de Neftali Reyes.
En versos aislados, Shakespeare no identifica personajes, tampoco mueve batallas o cuenta desacatos; únicamente dibuja imágenes sobre lo blanco del papel. Sobre los escenarios, reconoce quién hace, habla y desfila con sus peripecias; muestran un túnel

...por el que sopla un viento fantasmagórico. El sonido más viejo del mundo, el sonido del corazón humano va formando las palabras inolvidables. Todo esto está desgranado en las tragedias, junto a las interjecciones del pueblo, a las insignias de los mercados, a las sílabas soeces de parásitos y bufones, entre el choque del acero y las panoplias enloquecidas ${ }^{13}$.

Ante uno y otro espectáculo, Neruda se inclina a favor del Shakespeare poeta, que brota desmedido y estampa en los muros del tiempo, usando el azul, la espuma mágica de tantos versos brindados a la eternidad. Cuando era joven, y desde sus residencias en la tierra, Neruda guarda memoria de un amigo que le dio, junto a otros, leyes cristalinas:

Porque la poesía de Shakespeare, como la de Góngora y la de Mallarmé, juegan con la luz de la razón, impone un código estricto, aunque secreto. En una palabra, en aquellos años abandonados de mi vida, la poesía shakesperiana mantuvo en mí abierta comunicación con la cultura occidental. Al decir esto, incluyo naturalmente a Pushkin y Kart Marx, a Bach y al Hölderlin, a Lord Tensión y a Mayakovski ${ }^{14}$.

Bien mirado, ese otro Shakespeare tiene cierto parecido a quién lo describe, porque vuelve a fantasear con él hurgando a solas en las entrañas de unas historias comunes. Los trucos de Shakespeare ya los anunció suyos, desde su primer Confabulario, Pablo Neruda:

Yo lo comprendo, amigos, yo lo comprendo todo.

Se mezclaron voces ajenas a las mías,

Yo lo comprendo, amigos!

$[\ldots]$
Vinieron las palabras, y mi corazón Incontenible como un amanecer, Se rompió en las palabras y se apegó a su vuelo, $Y$ en sus fugas heroicas lo llevan y lo arrasan, Abandonado y loco, y olvidado bajo ellas Como un pájaro muerto, debajo de sus alas ${ }^{15}$.

$$
\text { *** }
$$

Pero estos ojos míos son cándidos y tristes: No como yo los quiero ni como deba ser. Es que estos ojos míos el corazón los viste, Y su dolor los hace ver. *

El yo nerudiano, desde su origen, con legítimos balbuceos, en tránsito y por naturaleza, tiene siempre la voz de un poeta romántico que cifra experiencias, motivos y secretos en clave dramática:

Yo me llamaba Reyes, Catrileo, Arellano, Rodríguez, he olvidado Mis nombres verdaderos

Nací con apellido

De robles viejos, de árboles recientes, de madera silbante.

Yo fui depositado

En la hojarasca:

se hundió el recién nacido

en la derrota y en el nacimiento

de selvas que caían

y casas pobres que recién lloraban.

Yo no nací sino que me fundaron: me pusieron todos los nombres a la vez, todos los apellidos:

me llamé matorral, luego ciruelo,

alerce y luego trigo,

por eso soy tanto y tan poco, tan multitud y tan desamparado, porque vengo de abajo,

de la tierra ${ }^{16}$. 